\section{Measuring Monetary Policy Inertia in Target Fed Funds Rate Changes}

\section{Michael Dueker}

nflation in the United States has been relatively low and stable following the difficult disinflation during the early 1980s. Since then, the Federal Reserve has been perceived as following policies designed to preempt rising inflation. At the same time, empirical studies of Federal Reserve policy actions find that policy responses are generally stodgy and that a great deal of interest rate smoothing takes place, relative to rule-based policy prescriptions, such as the Taylor rule (Taylor, 1993). Several explanations have arisen as to why a central bank that is focused primarily on inflation control would exhibit policy inertia when changes seem indicated. Rudebusch (1999) and Orphanides (1998) study data uncertainty as a possible justification for stodgy policy responses, because revisions take place before estimates of output and price indices are final and policymakers want to avoid acting on false signals. This justification falls under the umbrella of recognition lags in that it takes time for monetary policymakers to observe that inflation has moved decisively upward or that an output gap has developed. Sack (1998) suggests that uncertainty regarding the structure of the economy may be a reason for the Federal Reserve to respond cautiously. Goodfriend (1997) notes that if aggressive Federal Reserve actions subsequently proved to be mistimed, the public's trust in the Fed would diminish. Hence, policymakers might tend to act less aggressively, again due to uncertainty regarding the timeliness of currently contemplated policy actions. Woodford (1999) offers a different explanation of policy inertia that is not based on model or instrument uncertainty. In Woodford's view, every policy action also is a hint of how policy will be conducted in the future. In this case, part of the central bank's credibility rests on making current policy roughly consistent with the path to which it had hinted through earlier policies. In this case, some policy inertia results as policymakers balance their impetus to respond to current news against their implicit prior commitment to a particular path for interest rates.

This article presents two distinct measures of inertia in the target fed funds rate, relative to the prescriptions of Taylor's (1993) policy rule, including the inertia inherent in the discreteness of the target fed funds rate. Previous empirical estimates of policy inertia have not addressed the discrete nature of target funds rate changes; instead, they use quarterly or monthly averages of the funds rate, which can mask an important feature of the policymaking process. The Federal Open Market Committee (FOMC) sets its objective, or target, for the federal funds rate, the interest rate that banks charge each other for overnight loans of Federal Reserve deposits. In practice, the FOMC usually changes the target fed funds rate in discrete amounts by multiples of 25 basis points. Thus, an important facet of policy inertia takes the form of the following question: How far does the FOMC let the prevailing target funds rate get out of line, relative to a shadow desired level that changes continuously? Another facet, which has been the subject of previous study, is the degree to which the fed funds rate obeys a partial-adjustment mechanism and the sluggishness implied by such a mechanism. A joint view of these two 
facets of policy inertia ought to provide a more complete picture, from which subsequent research can investigate whether policy appears to display either too much or the right amount of inertia.

In particular, this article presents an econometric model of discrete changes in the target fed funds rate in order to estimate thresholds at which the FOMC decides to change the target and by how much. The model defines a latent desired target level, so the threshold coefficients represent the sizes of gaps between the desired and actual target funds rates that are necessary to induce target changes of various sizes. These estimated thresholds are compared with the sizes of the actual changes in the target fed funds rate- usually 25 or 50 basis points- to arrive at a quantitative measure of the Fed's readiness or reticence to initiate changes in the target funds rate. The complete set of threshold coefficients also provides estimates of cutoff levels at which the Fed chooses to make either a small or large change in the target funds rate. The payoff to estimating threshold coefficients is that we can then separate any slugghishness in changes to the target fed funds rate introduced by its discrete nature from sluggishness due to data or model uncertainty. Also, tests for asymmetry in the thresholds between increases and decreases in the target funds rate are possible.

\section{DISCRETE NATURE OF TARGET CHANGES}

The discrete nature of changes in the target fed funds rate poses special challenges to empirical analysis. Almost all changes in the target funds rate are in multiples of 25 basis points. In this article, I use data on the target funds rate that start in 1985 (Rudebush, 1995). A plot of the target funds rate is shown in Figure 1. To match the frequency of some of the explanatory variables, I calculate the change in the target funds rate from the last business day of the month to the last business day of the previous month. Prior to 1990 , some changes were as small as six basis points, with some other small changes of 12.5 basis points. I classified monthly changes of less than 18 basis points as "no change" with two exceptions: In September 1985 and November 1988 the target funds rate increased by 12.5 basis points for the second month in a row; I counted the combined change as a 25 basis point increase during the second month.

Table 1 summarizes the five discrete categories I use for the changes in the target funds rate, where the target funds rate is denoted $\mathrm{FF}^{\top}$. The last column shows that, despite a number of odd-sized changes in the target through 1989, the means within the five categories correspond very closely to multiples of 25 basis points: $(-.50,-.25,0,+.25,+.50)$. The target funds rate has decreased on net since 1985, resulting in more 25 basis point decreases than increases.

\section{TAYLOR'S RULE IGNORING DISCRETENESS}

Following Judd and Rudebusch (1998), I use Taylor's rule to motivate an empirical specification for modeling changes in the federal funds rate. Taylor (1993) suggested that the FOM C's behavior from 1987 to 1992, with respect to setting a target for the federal funds rate, appeared to be wellsummarized by a simple monetary policy rule. This interest-rate rule, which became known as Taylor's rule, is one in which the Federal Reserve changes its objective for the federal funds rate in response to the gap between the actual and desired levels of inflation, and to the percentage gap between actual and potential output. In its original specification, Taylor's rule takes the following form under the assumptions that the FOM C's long-run desired rate of inflation is 2 percent and that the equilibrium real short-term interest rate al so is 2 percent (Orphanides, 1998):

$$
F F_{t}=1+1.5 \pi_{\mathrm{t}}+.5\left(\mathrm{y}-\mathrm{y}^{\mathrm{p}}\right)_{\mathrm{t}^{\prime}}
$$

where F $F$ stands for the federal funds rate, $\pi$ for the inflation rate, $y$ for the log of 
actual output and $y^{p}$ for the log of potential output. In long-run equilibrium, the output gap will be zero and the equilibrium real rate of interest ( $F F-\pi$ ) will equal two by assumption. Thus, equation 1 implies a long-run inflation target of 2 percent.

The most important empirical lesson from Taylor's rule has not been to check whether actual policy is consistent with 2 percent inflation, however. Instead, Taylor (1998) gives considerable importance to the coefficient on inflation having an absolute value greater than one, because if the Fed were to raise the fed funds rate by more than any increase in inflation, then the real interest rate would increase, thereby dampening inflationary pressures in the economy. Any policy equation in which the response of the nominal interest rate instrument to a change in inflation is greater than one is said to have the Taylor-rule property, regardless of the implied long-run inflation target. In empirical research, Taylor's original equation often is modified to include a lagged dependent variable. Rules with gradual adjustment have the Taylor property if the long-run response of the interest-rate instrument to a change in inflation is greater than one:

$$
\begin{aligned}
& \mathrm{FF}_{\mathrm{t}}=\rho \mathrm{FF}_{\mathrm{t}-1}+\lambda_{0}+\lambda_{1} \pi_{\mathrm{t}} \\
& +\lambda_{2}\left(\mathrm{y}-\mathrm{y}^{\mathrm{p}}\right)_{\mathrm{t}}+\delta \Delta \mathrm{FF}_{\mathrm{t}-1} \\
& \lambda_{1} /(1-\rho)>1
\end{aligned}
$$

For positive values of $\rho$, equation 2 allows for more gradual adjustment of the federal funds rate to changes in inflation. Sack (1998) and Judd and Rudebusch (1998) have used such a partial adjustment approach to model FOMC policy. The caveat is that ordinary least squares estimation of the partialadjustment mechanism from equation 2 ignores the discreteness in the actual changes to the target fed funds rate. Estimates of equation 2 with monthly data starting in 1985 appear in Table 2, where $\pi$ is the year-over-year inflation rate calcu-

\section{Figure 1}

Fed Funds Target

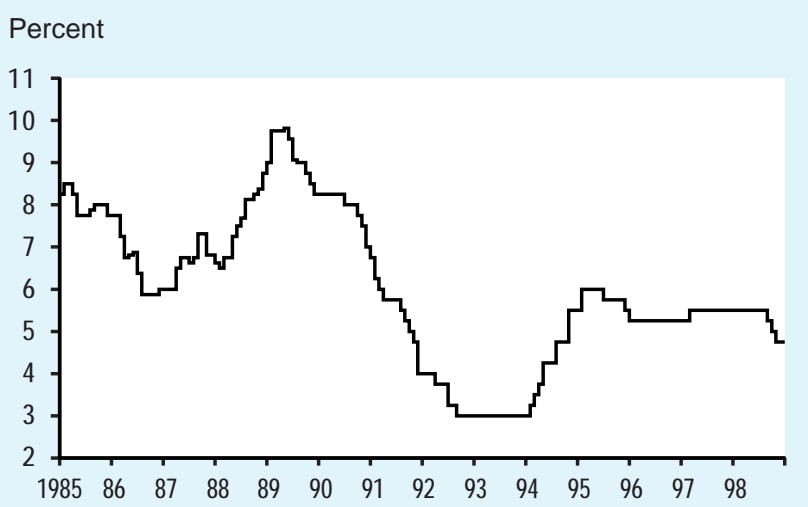

\section{Table 1}

Observation Categories Based on Size of Target Rate Change.

Monthly Sample: 1/85 - 12/98

\begin{tabular}{c|l|c|l} 
Category & \multicolumn{1}{c}{ Criterion } & Frequency & Mean D FFT within category \\
\cline { 1 - 3 } \cline { 3 - 4 } 1 & \multicolumn{1}{c}{$\Delta \mathrm{FF}^{\top}<-.25$} & 11 & -.523 \\
2 & $-.25 \leq \Delta \mathrm{FF}^{\top} \leq-.18$ & 25 & -.248 \\
3 & $-.18<\Delta \mathrm{FF}^{\top}<+.18$ & 111 & +.0056 \\
4 & $+.18 \leq \Delta \mathrm{FF}^{\top} \leq+.25$ & 10 & +.244 \\
5 & $\Delta \mathrm{FF}^{\top}>+.25$ & 10 & +.538
\end{tabular}

lated from the consumer price index without the food and energy components. The funds rate data, FF, are the monthly averages of the effective funds rate in the upper panel of Table 2 and are the end-ofmonth values of the target fed funds rate in the lower panel of Table 2. The log of real GDP (deflated by the chain-weighted price index) is $y$, and $y^{P}$ is the log of the potential output series from the Congressional Budget Office. Note that $y$ and $y^{p}$ only are available at the quarterly frequency. The output gap tends to evolve slowly, however, so I used the same value of the output gap for three months running in order to estimate equation 2 at a monthly frequency. Figure 2 plots the output gap since 1985 in logs, so that 100 times the log gap is the output gap as a percentage.

Table 2 shows that for either 


\section{Table 2}

Estimated Taylor Rules from Equation 2 Monthly Data: 1/85 - 12/98

\begin{tabular}{|c|c|c|c|}
\hline \multirow[t]{2}{*}{ Coef cient } & Description & Value & Std. Error \\
\hline & \multicolumn{3}{|c|}{ Results for Effective Funds Rate } \\
\hline$\lambda_{1}$ & Inflation & 0.086 & 0.044 \\
\hline$\lambda_{2}$ & Output Gap & 0.063 & 0.022 \\
\hline$\rho$ & Autoregression & 0.937 & 0.022 \\
\hline$\delta$ & Lagged change & 0.379 & 0.074 \\
\hline \multirow[t]{2}{*}{$\lambda_{0}$} & Constant & 0.061 & 0.072 \\
\hline & \multicolumn{3}{|c|}{ Results for Target Funds Rate } \\
\hline$\lambda_{1}$ & Inflation & 0.080 & 0.044 \\
\hline$\lambda_{2}$ & Output Gap & 0.065 & 0.023 \\
\hline$\rho$ & Autoregression & 0.939 & 0.023 \\
\hline$\delta$ & Lagged change & 0.342 & 0.075 \\
\hline$\lambda_{0}$ & Constant & 0.068 & 0.072 \\
\hline
\end{tabular}

\section{Figure 2}

Real GDP and Real Potenial GDP (in Logs)

$\log$

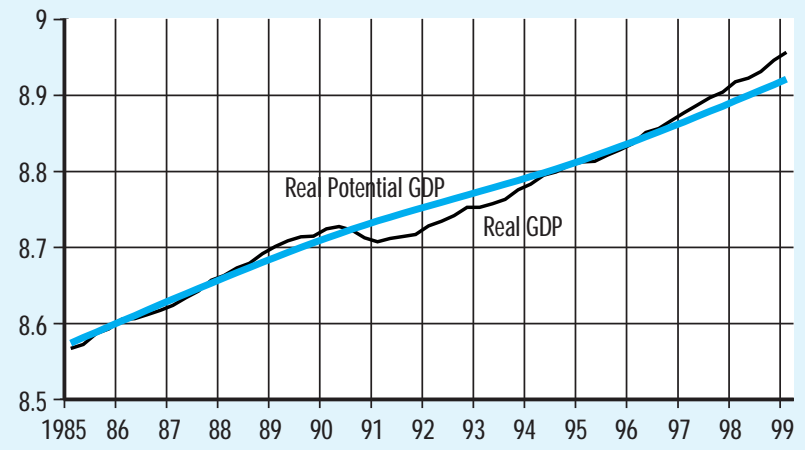

dependent variable the long-run response of the funds rate to a percentage point increase in inflation is greater than one $\lambda_{1} /(1-\rho)=1.37$ for the effective fed funds rate and 1.31 for the target fed funds rate. In Table 2, the estimated long-run response of the funds rate to a one percentage point increase in the output gap, $\lambda, /(1-\rho)$, is about one, which is larger than the 0.5 coefficient Taylor wrote in his original rule. Judd and Rudebusch (1998) also find that estimated feedback coefficients on the output gap are larger than originally specified by Taylor in equation 1.

\section{A DISCRETE EMPIRICAL MODEL WITH THRESHOLDS}

In this section, I examine a Taylor-rule specification of the target federal funds rate in an ordered probit model that has been enhanced with time-series features. An ordered probit model, unlike the ordinary least-squares regression from Table 2 , takes into account the discrete nature of target changes. As mentioned in the introduction, the discrete-variable model includes threshold coefficients that provide information on another possible manifestation of policy inertia: the degree of interest-rate misalignment required to induce a discrete change in the target level of the funds rate.

The five categories defined in Table 1 fit naturally into an ordered probit framework. As in probit models in general, one assumes that there is a continuous latent or desired level of the target funds rate, which is denoted as $\mathrm{FF}^{\mathrm{T}^{*}}$. A standard assumption in probit models is that the latent variable is a linear function of some lagged explanatory variables, $X$, plus a normally distributed, mean-zero error term, $\varepsilon$ :

$$
\mathrm{FF}_{\mathrm{t}}^{\top *}=\mathrm{X}_{\mathrm{t}-1}^{\prime} \beta+\varepsilon_{\mathrm{t}} .
$$

In keeping with the Taylor-rule specification of equation 2 , the $X$ variables are inflation, the output gap, and an intercept. Given the evidence of a partial-adjustment mechanism from the estimates of equation 2 , I also add a lagged dependent variable and the lagged change in the dependent variable to equation 3, following Judd and Rudebusch (1998):

$$
\begin{aligned}
& \mathrm{FF}_{\mathrm{t}}^{\top *}=\rho \mathrm{FF}_{\mathrm{t}-1}^{\top *}+\lambda_{0}+\lambda_{1} \pi_{\mathrm{t}} \\
& +\lambda_{2}\left(\mathrm{y}-\mathrm{y}^{\mathrm{p}}\right)_{\mathrm{t}}+\delta \Delta \mathrm{FF}_{\mathrm{t}-1}^{\top *}+\varepsilon_{\mathrm{t}}
\end{aligned}
$$

The assumed mapping between the latent variable and the observable discrete 
changes in the target funds rate is

$$
\begin{aligned}
& \Delta F_{t}^{\top} \text { is in category } j \text { if } \\
& F F_{t}^{\top *}-F F_{t-1}^{\top} \text { is in }\left(c_{j-1}, c_{j}\right),
\end{aligned}
$$

where the categories are defined in Table 1 and $\mathrm{c}$ is a vector of threshold coefficients. The difference $F_{t}{ }^{*}-F F_{t-1}^{\top}$ represents the latent "desired" change in the target funds rate, as defined by the econometric model. The estimated threshold coefficients indicate the degree of underlying pressure that is needed to induce a discrete change in practice. For the threshold coefficients to have this meaning, the latent variable must be restricted to economically relevant values. I do this by constraining the intercept such that the mean of the latent variable is the same as the mean of the observed target rate:

$$
\overline{\mathrm{FF}^{\mathrm{T}}}=\overline{\mathrm{FF}^{\mathrm{T}}}=5.91 \text {. }
$$

This restriction implies that the discrete variable has the same sample-wide mean as the continuous latent variable.

\section{MODEL ESTIMATION}

The log-likelihood function for the observed changes in the target fed funds rate is

$$
\begin{aligned}
& \operatorname{lnf}\left(\Delta \mathrm{FF}_{\mathrm{t}}^{\top}\right)=\sum_{\mathrm{j}=1}^{5} \mathrm{D}(\text { cat.j }) \\
& \ln \left\{\left[\Phi \left(\left(\mathrm{FF}_{\mathrm{t}-1}^{\top}-\rho \mathrm{EFF}_{\mathrm{t}-1}^{\top *}\right.\right.\right.\right. \\
& -\lambda_{1} \pi_{\mathrm{t}-1}-\lambda_{2}\left(\mathrm{y}-\mathrm{y}^{\mathrm{p}}\right)_{\mathrm{t}-1} \\
& \left.\left.-\delta \mathrm{E} \Delta \mathrm{FF}_{\mathrm{t}-1}^{\top *}+\mathrm{c}_{\mathrm{j}}\right) / \sigma\right) \\
& -\Phi\left(\left(\mathrm{FF}_{\mathrm{t}-1}^{\top}-\rho \mathrm{EFF}_{\mathrm{t}-1}^{\top *}\right.\right. \\
& -\lambda_{1} \pi_{\mathrm{t}-1}-\lambda_{2}\left(\mathrm{y}-\mathrm{y}^{\mathrm{p}}\right)_{\mathrm{t}-1} \\
& \left.\left.\left.\left.\delta \mathrm{E} \Delta \mathrm{FF}_{\mathrm{t}-1}^{\top *}+\mathrm{C}_{\mathrm{j}-1}\right) / \sigma\right)\right]\right\}_{,}
\end{aligned}
$$

where $\Phi($.$) is the cumulative normal$ density function and $D$ (cat. $j$ ) is a dummy variable for category $j$ at time t. For the lagged dependent variable, $\mathrm{FF}_{\mathrm{t}}{ }^{*}$, we need to take an expected value, because we do not observe the realized residual, $\varepsilon$. Therefore, we use

$$
\begin{aligned}
& \mathrm{EFF}_{\mathrm{t}}^{\mathrm{*} *}=\rho \mathrm{EFF}_{\mathrm{t}-1}^{\mathrm{*}}+\lambda_{0} \\
& +\lambda_{1} \pi_{\mathrm{t}-1}+\lambda_{2}\left(\mathrm{y}-\mathrm{y}^{\mathrm{p}}\right)_{\mathrm{t}-1} \\
& -\delta \mathrm{E} \Delta \mathrm{FF}_{\mathrm{t}-1}^{\top *}+\mathrm{E}\left[\varepsilon_{\mathrm{t}} \mid \Delta \mathrm{FF}_{\mathrm{t}}\right. \\
& \text { is in cat.j }]
\end{aligned}
$$

$$
\begin{aligned}
& \mathrm{E}\left[\varepsilon_{\mathrm{t}} \mid \Delta \mathrm{FF}_{\mathrm{t}} \text { is incat.j }\right]= \\
& -\sigma /(2 \pi)^{.5}\left[\exp \left\{-c_{\mathrm{j}}^{2} /\left(2 \sigma^{2}\right)\right\}\right. \\
& \left.-\exp \left\{-c_{\mathrm{j}-1}^{2} /\left(2 \sigma^{2}\right)\right\}\right] \\
& / \mathrm{f}\left(\Delta \mathrm{FF}_{\mathrm{t}}^{\top}\right)
\end{aligned}
$$

where $\lambda_{0}$ is al ways restricted to make

$$
\begin{aligned}
& \overline{\mathrm{FF}^{T^{*}}}=\overline{\mathrm{FF}^{\top}}= \\
& 5.91, c_{j}>c_{j-1}, \\
& j=1, \ldots, 4, c_{0}=-\infty,
\end{aligned}
$$

and $c_{5}=\infty$.

The variance parameter, $\sigma^{2}$, was assigned a value and was not estimated, since we cannot identify jointly the threshold constants $c$ and the variance parameter. The value of $\sigma^{2}$ was set at 0.12 , which implies a standard deviation of the disturbance to the desired fed funds rate of about 35 basis points per month. If a much larger variance were chosen, the threshold constants would increase in absolute value, but some experimentation showed that estimates of the threshold coefficients are fairly stable across a range of plausible values of the variance. 


\section{Table 3}

Autoregressive Ordered Probit Model

of Target Fed Funds Rate

Monthly Sample: 1/85 - 12/98

\begin{tabular}{|c|c|c|c|}
\hline $\begin{array}{l}\text { Coef cient } \\
\text { (by variable) }\end{array}$ & Value & $\begin{array}{l}\text { Category mean } \\
\text { (from Table 1) }\end{array}$ & Std. Error \\
\hline Lagged EFF ${ }^{T^{*}}$ & 0.906 & & 0.032 \\
\hline Inflation & 0.152 & & 0.063 \\
\hline Output gap & 0.102 & & 0.029 \\
\hline Lagged EAFF ${ }^{T *}$ & 0.118 & & 0.067 \\
\hline Threshold $c_{1}$ & -0.799 & -0.523 & 0.186 \\
\hline Threshold $c_{2}$ & -0.439 & -0.248 & 0.191 \\
\hline Threshold $c_{3}$ & 0.459 & 0.244 & 0.191 \\
\hline Threshold $c_{4}$ & 0.658 & 0.538 & 0.188 \\
\hline
\end{tabular}

Log - Likelihood Value $=-150.4$ output gap also closely matches the estimates from the simple regresssions: $\lambda_{2} /(1-\rho)=1.09$.

In addition, the discrete-variable model provides information on the thresholds at which the FOMC tends to move the target funds rate. To induce either an increase or a decrease in the target of 25 basis points, the latent target funds rate, $\mathrm{FF}^{\top *}$, must be about 45 basis points above or below the actual target, according to the point estimates. In other words, the gap between the latent desired level of the target fed funds rate and the actual target level must be considerably larger than 25 basis points to induce a 25 basis-point change.

The symmetry of the threshold levels across increases and decreases suggests that the FOMC does not require more pressure to raise the target funds rate than to lower it. That is, we cannot come close to rejecting the hypothesis that $c_{2}+c_{3}=0$. Less obvious is the failure to reject symmetry across the thresholds for large target changes: $c_{1}+c_{4}=0$. The standard error on the sum is 0.36 , so we cannot reject symmetry for large changes either. The thresholds are significantly greater in absolute value than the 25 and 50 basispoint levels corresponding with the category means. We can easily reject the joint hypothesis that $c_{3}=-c_{2}=0.25$, and $c_{4}=-c_{1}=0.50$, with a Wald test statistic that has a probability value well below 0.001 . Similarly, the probability value of the Wald test that $c_{3}=-c_{2}=0.25$ is almost equally low. Thus, the threshold coefficients reveal significant evidence that the discrete nature of the target federal funds rate adds a dimension of sluggishness to monetary policy responses to inflation and output gaps that goes beyond the partial adjustment specification of equations 2 and 4.

\section{SUMMARY AND CONCLUSIONS}

Previous studies have shown that movements in the federal funds rate can be described by a Taylor-rule equation with interest-rate smoothing via a partial adjust- 
ment mechanism. The contribution of this article is to examine the smoothing or policy inertia within a model of discrete target funds rate changes. To do so, I estimate the thresholds that govern the relationship between an underlying partial-adjustment model of the latent or desired target level and the discrete changes observed in practice. The estimates show a substantial degree of sluggishness in the discrete responses of the target level of the funds rate to gaps between the underlying desired target level and the actual target level. N evertheless, the estimated threshold coefficients are less than twice the size of their corresponding discrete changes, so that there is a limit to the size of any misalignment of the target funds rate brought by its discrete nature. Furthermore, the estimates of the parameters that govern the latent desired level of the target funds rate display the long-run responsiveness property that Taylor (1998) associates with a sound inflation-fighting policy rule.

In addition, one area where the estimates of threshold coefficients would be useful is the federal funds futures market. Market participants would not want to forecast the fed funds target rate changes using ordinary least-squares estimates, given that discrete target changes face substantial threshold hurdles. With estimates of the thresholds, participants in the fed funds futures market can gauge more accurately the likelihood of a change in the target level in the near term, and thereby more accurately forecast the future monthly average for the federal funds rate.

\section{REFERENCES}

Goodfriend, Marvin. "Interest Rate Policy and the Inflation Scare Problem: 1979-1992" Federal Reserve Bank of Richmond Economic Quarterly (Winter 1993), pp. 1-24.

\footnotetext{
. "Monetary Policy Comes of Age: A 20th Century Odyssey,"

Federal Reserve Bank of Richmond Economic Quarterly (Winter 1997), pp. 1-22.

Huh, Chan G., and Kevin J. Lansing. "Federal Reserve Credibility and Inflation Scares," Federal Reserve Bank of San Francisco Economic Review (1998), pp. 3-16.
}

Judd, John P., and Glenn D. Rudebusch. "Taylor's Rule and the Fed: 1970-1997," Federal Reserve Bank of San Francisco Economic Review (1998), pp. 3-16.

Orphanides, Athanasios. "Monetary Policy Evaluation with Noisy Information," Federal Reserve Board of Governors FEDS Working Paper 98.50 (November 1998).

Rudebusch, Glenn D. "Federal Reserve Interest Rate Targeting, Rational Expectations and the Term Structure." Joumal of Monetary Economics, (April 1995) pp. 245-74.

World," "Is the Fed Too Timid? Monetary Policy in an Uncertain
Weserve Bank of San Francisco Working Paper (March 1999).

Sack, Brian. "Does the Fed Act Gradually? A VAR Analysis," Federal Reserve Board of Govemors FEDS Working Paper 98-17 (March 1998).

Taylor, John B. "Discretion Versus Policy Rules in Practice," CamegieRochester Conference Series on Public Policy 39 (December 1993), pp. 195-214.

\footnotetext{
"Monetary Policy and the Long Boom," this Review

(November/ December 1998), pp. 3-11.

Woodford, Michael. "Optimal Monetary Policy Inertia," 1999 manuscript, Princeton University.
} 


\section{HeVIIII \\ SEPTEMBER/ OCTOBER 1999}

FEDERAL RESERVE BANK OF ST. LOUIS 